\title{
The Mechanical Properties of PVC Nanofiber Mats Obtained by Electrospinning
}

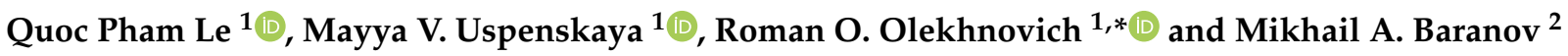 \\ 1 Institute BioEngineering, ITMO University, Kronverkskiy Prospekt, 49A, 197101 St. Petersburg, Russia; \\ quocphampro@gmail.com (Q.P.L.); mv_uspenskaya@mail.ru (M.V.U.) \\ 2 Center of Information Optical Technology, ITMO University, Kronverkskiy Prospekt, 49A, \\ 197101 St. Petersburg, Russia; mbaranov@mail.ru \\ * Correspondence: r.o.olekhnovich@mail.ru
}

check for updates

Citation: Pham Le, Q.; Uspenskaya, M.V.; Olekhnovich, R.O.; Baranov, M.A. The Mechanical Properties of PVC Nanofiber Mats Obtained by Electrospinning. Fibers 2021, 9, 2. https://doi.org/10.3390/fib9010002

Received: 17 November 2020 Accepted: 23 December 2020 Published: 5 January 2021

Publisher's Note: MDPI stays neutral with regard to jurisdictional clai$\mathrm{ms}$ in published maps and institutional affiliations.

Copyright: (C) 2021 by the authors. Licensee MDPI, Basel, Switzerland. This article is an open access article distributed under the terms and conditions of the Creative Commons Attribution (CC BY) license (https:// creativecommons.org/licenses/by/ $4.0 /)$.

\begin{abstract}
This paper investigates the mechanical properties of oriented polyvinyl chloride (PVC) nanofiber mats, which, were obtained by electrospinning a PVC solution. PVC was dissolved in a solvent mixture of tetrahydrofuran/dimethylformamide. Electrospinning parameters used in our work were, voltage $20 \mathrm{kV}$; flow rate $0.5 \mathrm{~mL} / \mathrm{h}$; the distance between the syringe tip and collector was $15 \mathrm{~cm}$. The rotating speed of the drum collector was varied from 500 to $2500 \mathrm{rpm}$ with a range of $500 \mathrm{rpm}$. Nanofiber mats were characterized by scanning electron microscope, thermogravimetric analysis, differential scanning calorimetry methods. The mechanical properties of PVC nanofiber mats, such as tensile strength, Young's modulus, thermal degradation, and glass transition temperature were also analyzed. It was shown that, by increasing the collector's rotation speed from 0 (flat plate collector) to $2500 \mathrm{rpm}$ (drum collector), the average diameter of PVC nanofibers decreased from $313 \pm 52$ to $229 \pm 47 \mathrm{~nm}$. At the same time, it was observed that the mechanical properties of the resulting nanofiber mats were improved: tensile strength increased from $2.2 \pm 0.2 \mathrm{MPa}$ to $9.1 \pm 0.3 \mathrm{MPa}$, Young's modulus from $53 \pm 14$ to $308 \pm 19 \mathrm{MPa}$. Thermogravimetric analysis measurements showed that there was no difference in the process of thermal degradation of nanofiber mats and PVC powders. On the other hand, the glass transition temperature of nanofiber mats and powders did show different values, such values were $77.5^{\circ} \mathrm{C}$ and $83.2{ }^{\circ} \mathrm{C}$, respectively.
\end{abstract}

Keywords: nanofiber; electrospinning; PVC; mechanical properties; the orientation of nanofibers; nonwoven mats

\section{Introduction}

In order to consider polymer fibers as nanofibers, their diameter size must be in a range from a few nanometers to over $1000 \mathrm{~nm}$ [1]. Therefore, nanofibers present a large surface area to volume ratio, high porosity, high aspect ratio, small pore size, low density, and mass transfer properties [2,3]. Many methods currently exist to produce polymer nanofibers such as drawing, phase separation, template synthesis, freeze-drying synthesis, self-assembly, interfacial polymerization of nanofibers, and electrospinning. Nowadays, electrospinning is known to be one of the most efficient methods to fabricate nanofibers on an industrial scale [4]. Due to the many advantages that electrospun nanofibers present, they have been found to have many uses in different fields such as air filtration [5-8], antibacterial [9], oil/water separation [10,11], tissue engineering scaffolding [12,13], drug delivery [14-16], reinforced polymer composites [17], sensors [18,19], and others.

Although, nanofiber mats have many advantages over previously known fibers, nanofiber mats exhibit low mechanical properties, thereby limiting their applicability [20]. Many studies indicate that it is necessary to enhance the mechanical properties of nanofiber mats for their applications, due to their low mechanical properties such as tissue engineering [21] and filter media [22,23]. The low mechanical strength of the nanofiber mats can be explained for the following reasons: high porosity, randomly arranged nanofibers 
and weak interaction between the nanofibers cross-points [23]. To solve the problem of the mechanical strength of the nanofiber mats, many methods have been used such as the synthesis of nanofiber mats from polymer blends [22], thermal treatments, solvent-vapor methods to strengthen the junction between the nanofiber by cross-linking the nanofiber together [24,25], and the fabrication a highly oriented nanofiber mat [26]. From the methods described above, the fabrication of a nanofiber mat with high nanofiber orientation, showed to be an effective and simple method to increase mechanical strength. Therefore, to improve the mechanical strength of the nanofiber mats, it is necessary to have a high level of alignment nanofibers [27]. To obtain highly aligned nanofiber mats by electrospinning, different receivers such as auxiliary electrodes [28], disc collectors [29], rotating drum collectors [30] can be used. The use of a rotating drum collector allows the fabrication of nanofiber mats with a large area.

Polyvinyl chloride (PVC) is one of the most common materials, used in different fields due to its high applicability. However, PVC nanofibers are only found in a few areas. For example, PVC/polystyrene (PS) nanofibers were used for oil spill cleanup [31]. Alarifi et al. [32] have reported that nanofibers made from PVC mixed with polyvinylpyrrolidone (PVP), were used for water treatment. In addition, PVC nanofiber mats were used as a corrosion inhibitor for metals in $\mathrm{NaCl}$ [33]. Nevertheless, the common disadvantage of the resulting materials is their low mechanical properties. In order to increase the mechanical strength of nanofiber mats and expand their scope, it is necessary to increase the degree of orientation of the nanofibers in the mat $[26,34,35]$. PVC is the cheapest polymer that can be found on the market; it has many advantages, such as, high resistance to acids, alkalis, and corrosion. PVC nanofibers have the potential to be used for water filtration, air filtration, and anti-corrosion materials. However, research on strengthening PVC nanofibers, using a rotating drum collector, is lacking in the literature.

In this study, we produce nanofibers by using a rotating drum collector, varying its speed from 0 to $2500 \mathrm{rpm}$ within an increasing range of $500 \mathrm{rpm}$. Analysis and evaluation of fibers orientation were done by a 2-D (two-dimensional) Fast Fourier transformation method using Photoshop and image software. The effect that different rotation speeds, of the rotating drum collector, have on nanofibers morphology, tensile strength, Young's modulus, differential scanning calorimetry, and thermogravimetric properties was studied and analyzed. Additionally, the influence that different orientations and diameters of the nanofiber affected the mechanical properties of the nanofiber mats was evaluated.

\section{Materials and Methods}

\subsection{Materials}

Polyvinyl chloride powder used in this study was supplied by Klyokner Pentaplast Rus Ltd. (Saint Petersburg, Russian Federation) with the molecular weight of $\bar{M} w=40,000 \mathrm{Da}$. $\mathrm{N}, \mathrm{N}$-dimethylformamide (DMF) 99.9\% was obtained from JSC EKOS-1 (Moscow, Russian Federation). Tetrahydrofuran (THF) 99.5\% was purchased from Chemmed Ltd. (Moscow, Russian Federation). All reagents were used as received without further purification.

\subsection{Fabrication of PVC Nanofibers}

PVC solution was prepared by dissolving the PVC powder in the DMF/THF systems (ratio volume of 50/50) at a temperature of $50{ }^{\circ} \mathrm{C}$ and a stirring speed of $300 \mathrm{rpm}$ with a $15 \%$ PVC weight concentration. Mixing was carried out for $3 \mathrm{~h}$ until the PVC dissolved completely. The prepared solution was kept at room temperature for $1 \mathrm{~h}$, in order to remove air bubbles and for stabilization.

PVC nanofibers were spun using a Nanofiber Electrospinning System NANON-01A (MECC CO., LTD., Fukuoka, Japan) with a flat plate (length $200 \mathrm{~mm}$, wide $150 \mathrm{~mm}$ ) and rotating drum (diameter $200 \mathrm{~mm}$, length $200 \mathrm{~mm}$ ) collectors at room temperature (Figure 1). A 5-mL syringe and needle tip 18G (1 mm inner diameter) were used. The electrospinning parameters used in our work were voltage $-20 \mathrm{kV}$; flow rate $-0.5 \mathrm{~mL} / \mathrm{h}$; the distance between the syringe tip and collector was $15 \mathrm{~cm}$. The rotating speed of the drum collector was 
varied from 500 to $2500 \mathrm{rpm}$ with a range of $500 \mathrm{rpm}$. For mechanical properties analysis, samples were collected after 10hrs of electrospinning work. For morphology and scanning electron microscope (SEM) analysis, samples were obtained after $15 \mathrm{~min}$ of electrospinning work. Non-oriented fibers mats were obtained from a flat plate collector, oriented fibers mats were obtained from the drum collector. Before any studies or characterizations were done, all samples were kept at a temperature of $25{ }^{\circ} \mathrm{C}$ and relative humidity less than $75 \%$ for a period of $48 \mathrm{~h}$.

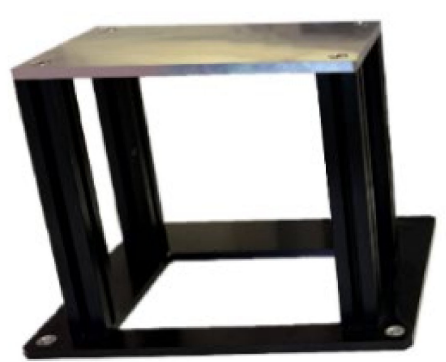

(a)

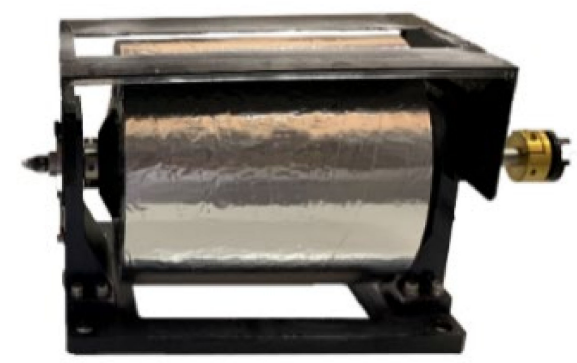

(b)

Figure 1. Types of collectors: (a)—flat plate collector, (b)—rotating drum collector.

\subsection{Methods}

The SEM images were obtained using a Supra 40 SEM-FEG (Zeiss, Germany). Diameters of the electrospun PVC fibers were measured with an image analyzer (ImageJ, National Institutes of Health, Bethesda, MD, USA). The average diameter of the nanofibers and the standard deviation were calculated based on measuring the diameter of 200 nanofibers selected randomly on three SEM images.

2-D Fast Fourier Transformation (FFT) was used for analysis of fiber orientation. In this method, the pixel intensity in an optical data image will be converted into a mathematically defined frequency domain [36]. Grayscale 8-bit images were cropped to $1000 \times 1000$ pixels for analysis. The used image-processing software ImageJ can apply the FFT rapidly to the photograph. Before performing an analysis of the orientation of the nanofiber mats, the contrast of the SEM images was increased with the tool "Curve" in Photoshop software. SEM images present a dark background, which can represent an obstacle when performing FFT analysis of nanofibers, mainly because some of the fibers are lost in the darkened areas. A color inversion was performed on the image, in which it is possible to see that the nanofibers are now black, and the background of the image is white. Convention is to place the $0^{\circ}$ position at 12:00 $\mathrm{o}^{\prime}$ clock on the unit circle and continue in a counterclockwise fashion with $90^{\circ}$ at 9:00 o'clock, $180^{\circ}$ at 6:00 o'clock, and $270^{\circ}$ at 3:00 o'clock. The information obtained from the FFT photograph can be quantified by measuring the radial sum intensity for 360 radii around the center of the FFT photograph using the tool "Oval Profile" of "ImageJ" software. After processing, the graph will describe the orientation of the fibers. The resulting graph will have 4 peaks that occur every $90^{\circ}$; the 2 higher peaks will correspond to the angles $0^{\circ}$ and $180^{\circ}$. A photograph with no alignment will show a constant pixel intensity absent of peaks, indicating no specific directionality. The FFT data were normalized to a baseline value of 0 and plots in arbitrary units from 0 to 0.1 . To determine the orientation of the fibers, we followed the steps outlined above, repeating the process three times.

The tensile properties were measured by using an Instron 5943 tensile testing machine (Instron, USA). All samples were tested in accordance with the ISO 527-3 standard [37] at room temperature and a speed test of $50 \mathrm{~mm} / \mathrm{min}$. The sample sizes were $100 \times 10 \mathrm{~mm}$ (length $\times$ wide). Measurements were performed at least five times, in order to determine tensile properties. The thickness of the test samples was measured by using a digital micrometer. Sample thickness is the mean value of the thickness measured at three different positions. In order to determine the tensile strength, the samples were divided in two groups. The first group was cut parallel to the direction of the nanofibers. The second group 
was cut in a perpendicular direction to the direction of the nanofiber. Figure 2 shows the assembled apparatus for the electrospinning experiments, as well, a sample prepared for mechanical testing is shown.

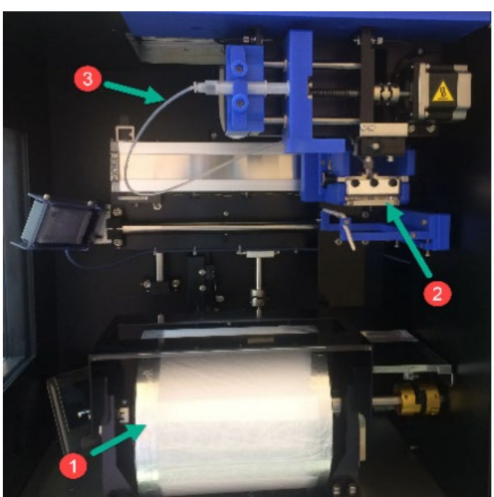

(a)

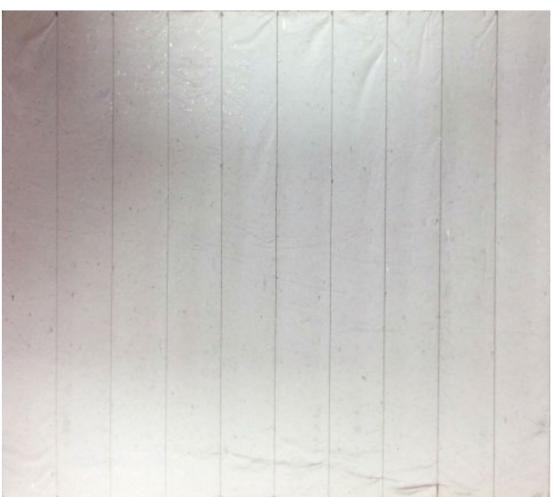

(b)

Figure 2. Nanofiber mat obtained by electrospinning process: (a)—electrospinning system (1—rotating drum collector; 2-spinneret; 3-a syringe and a Teflon tube were used to supply the solutions); (b) - sample for tensile testing.

Thermogravimetric analysis (TGA) was performed, by using a TG 209 F1 Libra (Netzsch, Germany) under a nitrogen atmosphere with a flow rate of $40 \mathrm{~mL} / \mathrm{min}$. The samples were studied on a range of temperatures that went from $25^{\circ} \mathrm{C}$ to $900{ }^{\circ} \mathrm{C}$ with an increasing rate of $10{ }^{\circ} \mathrm{C} / \mathrm{min}$. Differential scanning calorimetry (DSC) studies were performed, by using a DSC 204 F1 Phoenix (Netzsch, Germany) under a nitrogen atmosphere with a flow rate of $20 \mathrm{~mL} / \mathrm{min}$. The samples were heated from $-65{ }^{\circ} \mathrm{C}$ to $250{ }^{\circ} \mathrm{C}$ with an increasing rate of $10^{\circ} \mathrm{C} / \mathrm{min}$.

\section{Results and Discussion}

Figure 3 shows PVC nanofibers' SEM images and the nanofiber mats photoshopped photos for alignment analysis and directional analysis. As can be observed from the SEM images, not only are the fibers pulled during electrospinning, but droplets also are formed during the electrospinning process. Through image processing, the directional distribution of the fibers becomes clear, which makes the FFT method applied for the analysis easier.

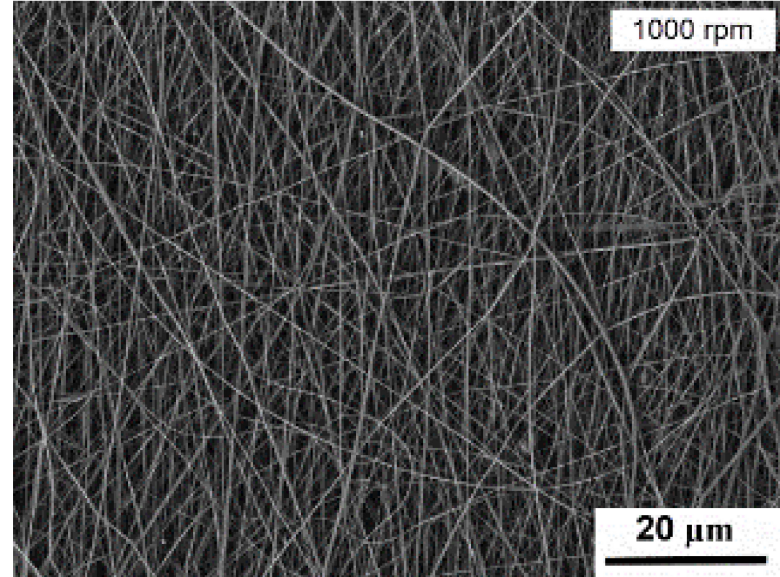

(a)

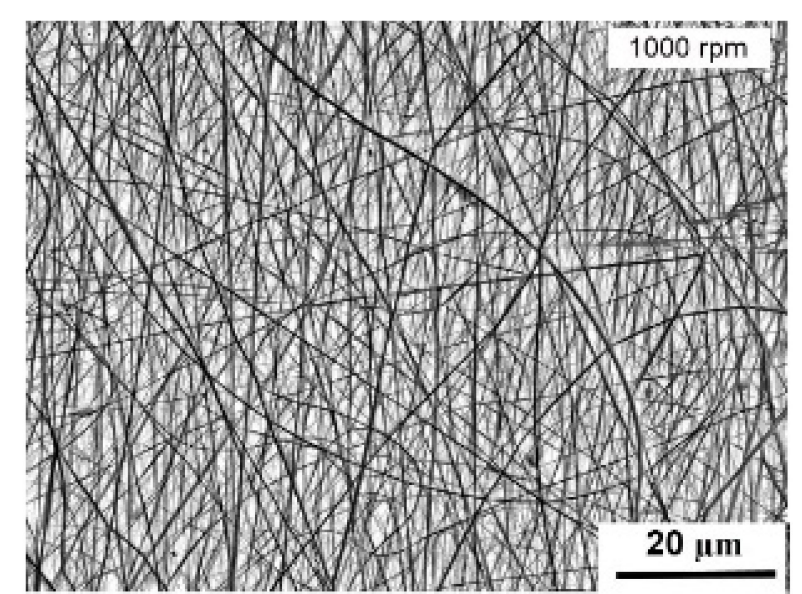

(b)

Figure 3. SEM image of polyvinyl chloride (PVC) nanofibers: (a)—before processing; (b)—after processing. 
Figure 4 shows diagrams of nanofibers' diameter distribution. The skew of nanofibers' sample diameter distribution collected at different speeds ( $|\mathrm{A}|$ ) is less than 0.5 ; thus, it is possible to use Gaussian distribution. Table 1 shows the average diameter of the obtained fibers. An increase in the rotational speed of the drum leads to a decrease in the average diameter of the nanofiber while the other parameters remain unchanged. The average diameter of the nanofibers decreases from $313 \pm 52 \mathrm{~nm}$ to $229 \pm 47 \mathrm{~nm}$ with an increase in the drum collector's rotation speed from $0 \mathrm{rpm}$ to $2500 \mathrm{rpm}$. The value of the standard deviation of the average diameter of the nanofibers remains almost constant. The decrease in the average diameter of the nanofibers is due to an increase in the speed of the rotating drum collector.

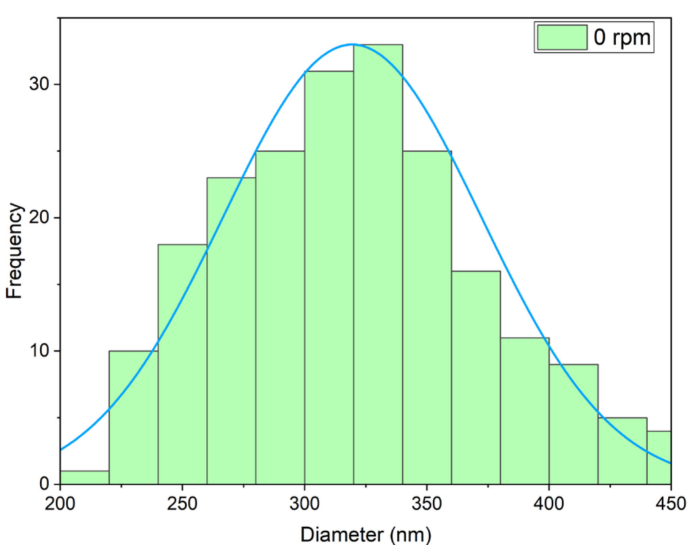

(a)

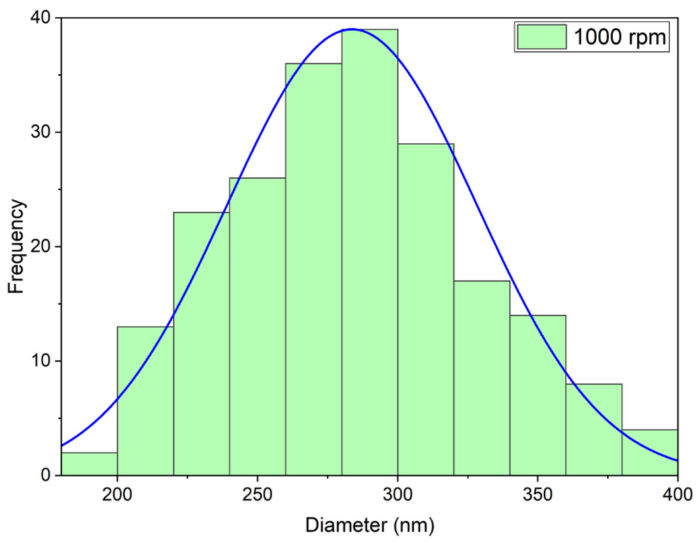

(c)

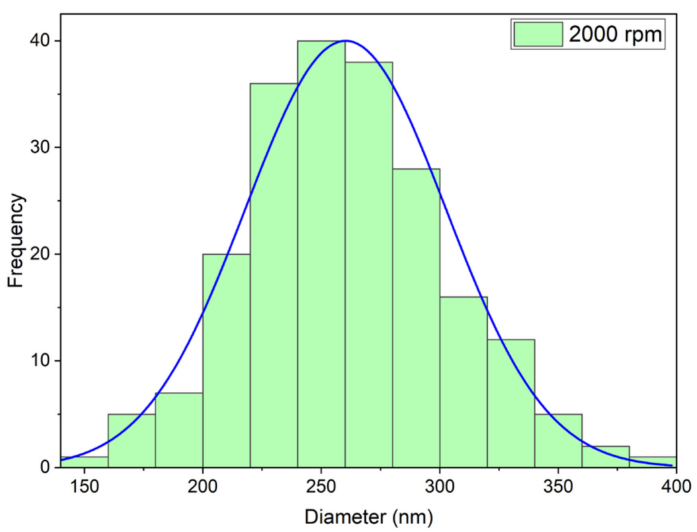

(e)

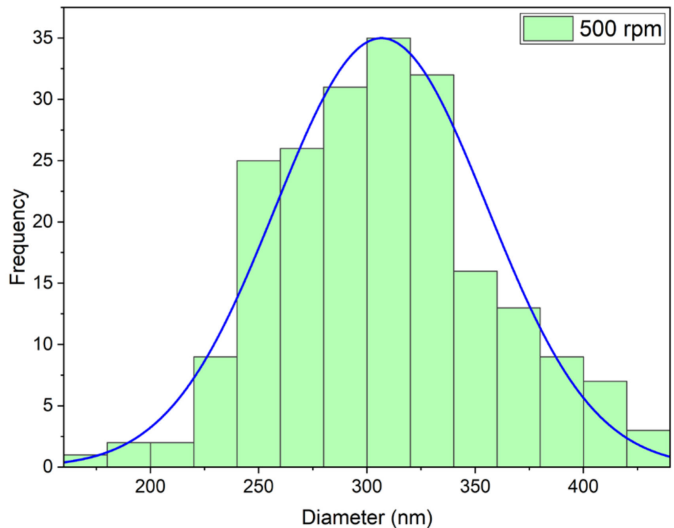

(b)

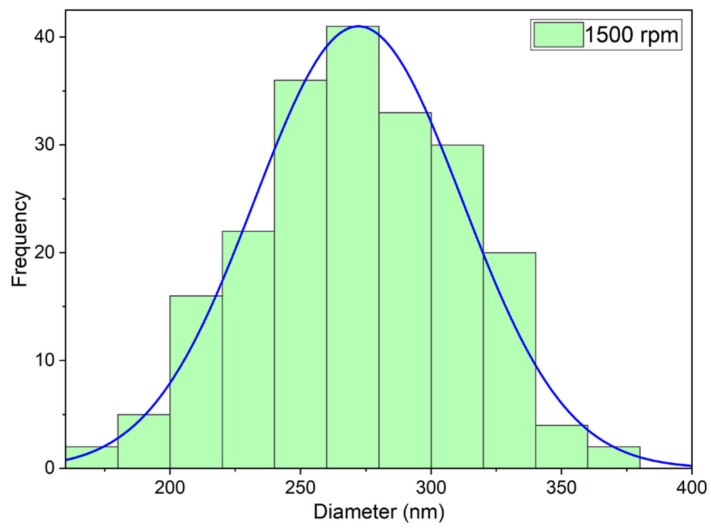

(d)

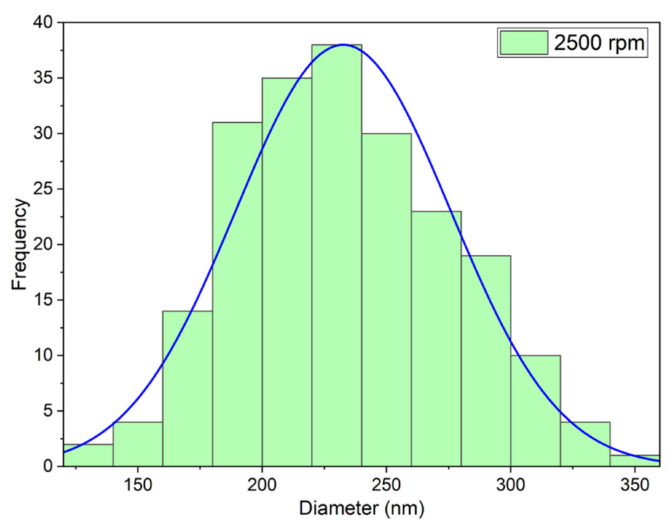

(f)

Figure 4. Diameter distribution of PVC nanofibers with different drum rotation speeds: (a) — 0 rpm (flat plate collector); (b) - $500 \mathrm{rpm}$; (c)—1000 rpm; (d) -1500 rpm; (e)—2000 rpm; (f) -2500 rpm. 
Table 1. The dependence of the mean nanofiber diameter on the rotation speed of the collector.

\begin{tabular}{ccccccc}
\hline Rotation Speed, $\mathbf{r p m}$ & $\mathbf{0}$ (Flat Plate Collector) & $\mathbf{5 0 0}$ & $\mathbf{1 0 0 0}$ & $\mathbf{1 5 0 0}$ & $\mathbf{2 0 0 0}$ & $\mathbf{2 5 0 0}$ \\
\hline Mean nanofiber diameter, $\mathrm{nm}$ & 313 & 302 & 280 & 272 & 256 & 229 \\
Standard deviation $(\sigma), \mathrm{nm}$ & 52 & 46 & 43 & 47 & 39 & 47 \\
\hline
\end{tabular}

Figure 5 shows the results of the alignment analysis of nanofiber with different speeds of the rotating drum collector. The analysis results show that, when increasing the drum's rotation speed from 0 to 500, 1000, 1500, 2000 and 2500, the FFT Alignment (normalized) value increases from 0.031 to $0.035,0.066,0.073,0.095$ and 0.1 , respectively. When using a flat plate collector, the nanofibers lie randomly. An increase in FFT Alignment values indicates the formation of orientated nanofibers in the mats. When the rotation speed is greater than $1000 \mathrm{rpm}$ the value of FFT alignment peaks is greater than 0.065 , this demonstrates the potential to obtain aligned nanofibers, by increasing the drum collector's rotation speed. Therefore, an increase in the drum collector's rotation speed leads to the stabilization of the drawing process and a decrease in the number of droplets formed. SEM images revealed that, by increasing the rotation speed, the orientation of the obtained fibers also increases [38].

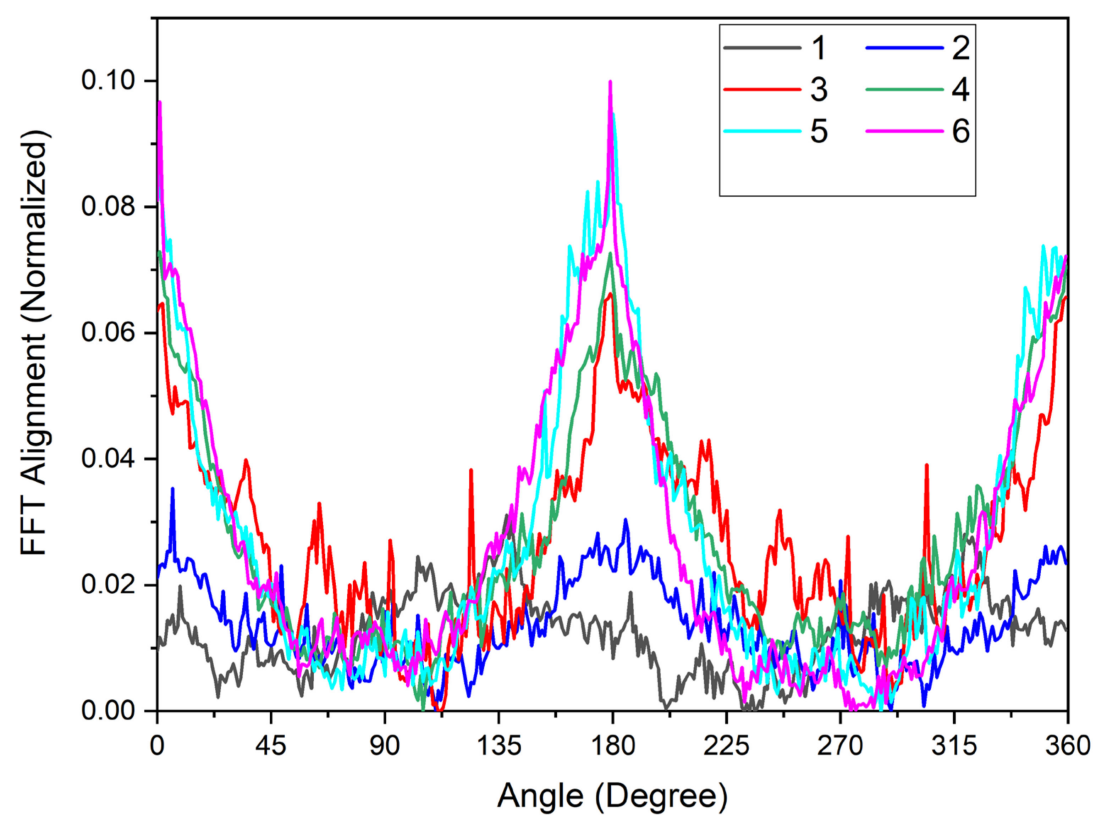

Figure 5. Alignment analysis and directional analysis: 1 - $0 \mathrm{rpm}$ (flat plate collector); 2 - $500 \mathrm{rpm}$; 3 - $1000 \mathrm{rpm}$; 4 - 1500 rpm; 5-2000 rpm; 6-2500 rpm.

The stress-strain diagrams of PVC nanofiber mats obtained from different rotational speeds are shown in Figure 6 and Table 2. From the stress-strain diagrams of PVC nanofiber mats, it is easy to notice that nanofiber mats obtained at a high rotation speed have more durability. In this work it was demonstrated that an increase in the drum collector's rotation speed leads to an increase in the mechanical strength of the nanofiber mats. Tensile strength increases from $2.2 \pm 0.2 \mathrm{MPa}$ to $9.1 \pm 0.3 \mathrm{MPa}$ and the Young's modulus from $53 \pm 14 \mathrm{MPa}$ to $308 \pm 19 \mathrm{MPa}$, respectively, with an increase in rotation speed from 0 to $2500 \mathrm{rpm}$. The change in elongation at break of the film is not very noticeable, with respect to the change in the drum collector's rotation speed, exhibiting an amount of about $30 \%$. Due to nanofiber entanglement in the mat, the value of the elongation at break is very small, which makes it almost unchangeable. Carrizales et al. [39] have reported that PVC nanofiber has a tensile strength of $2.2 \pm 0.2 \mathrm{MPa}$ and a modulus $12.3 \pm 2.6 \mathrm{MPa}$. These results are similar to the result we obtained from the sample at $0 \mathrm{rpm}$. The improvement of 
the nanofibers mats' mechanical properties can be explained by several reasons, which are going to be described below.

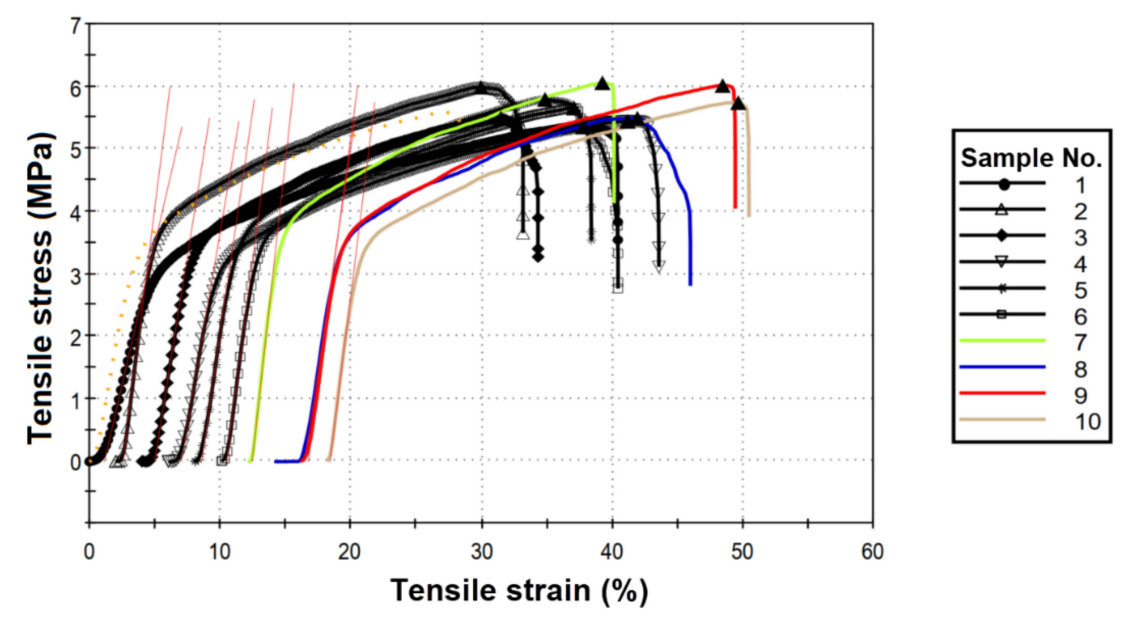

Figure 6. PVC nanofibers stress-strain diagrams, with rotation speeds of the collector at $1000 \mathrm{rpm}$.

Table 2. Mechanical properties of PVC nanofiber mats with parallel orientated nanofiber.

\begin{tabular}{ccccc}
\hline Rotation Speed $(\mathbf{r p m})$ & $\begin{array}{c}\text { The Thickness of } \\
\text { Nanofiber Mats }(\boldsymbol{\mu m})\end{array}$ & $\begin{array}{c}\text { Tensile Strength, } \\
\boldsymbol{\sigma}_{\text {at break }}(\mathbf{M P a})\end{array}$ & $\begin{array}{c}\text { Young's Modulus, } \\
\mathbf{E}(\mathbf{M P a})\end{array}$ & $\begin{array}{c}\text { Elongation at Break, } \\
\boldsymbol{\varepsilon}_{\text {at break }}(\mathbf{\%})\end{array}$ \\
\hline 0 & $73 \pm 10$ & $2.2 \pm 0.2$ & $53 \pm 14$ & $26 \pm 3$ \\
500 & $33 \pm 3$ & $3.0 \pm 0.3$ & $64 \pm 13$ & $31 \pm 7$ \\
1000 & $33 \pm 3$ & $5.7 \pm 0.3$ & $147 \pm 28$ & $30 \pm 4$ \\
1500 & $25 \pm 2$ & $5.2 \pm 0.4$ & $150 \pm 17$ & $28 \pm 5$ \\
2000 & $31 \pm 2$ & $6.1 \pm 0.6$ & $308 \pm 19$ & $30 \pm 4$ \\
\hline
\end{tabular}

Firstly, the anisotropy mechanical is a major factor that affects the mechanical properties of the nanofiber mats. When the nanofibers are randomly distributed, the strength of the mat is lower than that of oriented nanofibers. Moreover, when the drum collector's rotation speed is greater than $1000 \mathrm{rpm}$, the obtained nanofibers exhibited a better alignment orientation [40,41]. The orientation of the nanofibers increases the strength of the nanofiber mats. Specifically, we can observe this improvement by comparing the mats obtained at $500 \mathrm{rpm}$, with tensile strength and Young's modulus of $3.0 \pm 0.3 \mathrm{MPa}$ and $64 \pm 13 \mathrm{MPa}$, respectively, with the mat obtained at $1000 \mathrm{rpm}$ which has a tensile strength and Young's modulus was $5.7 \pm 0.3 \mathrm{MPa}$ and $147 \pm 28 \mathrm{MPa}$, respectively.

Secondly, several studies reported that a decrease in fiber diameter of approximately $700 \mathrm{~nm}$ leads to a change in tensile modulus and strength modulus. This change becomes even more pronounced when the diameter of the nanofiber is below $700 \mathrm{~nm}$. Nanofiberbased studies have shown that as the fiber diameter decreases to a critical value, the mechanical properties increase exponentially. When the diameter of the nanofiber is entangled between molecules, the structure of nanofiber will present fewer defects and a more uniform structure, leading to higher durability [42-44]. Therefore, the increase in the durability of nanofiber mats can be explained by the decrease in nanofiber diameter, which goes from $313 \pm 52 \mathrm{~nm}$ to $219 \pm 47 \mathrm{~nm}$.

Thirdly, the tensile stress of the nanofiber mats depends on many factors, such as the chemical structure of the polymer, the molecular orientation, and the extension chain of the polymer. PVC is an amorphous polymer. The random or orderly arrangement of the amorphous phase determines the physical and mechanical properties of the nanofibers [45]. In the process of electrospinning under the action of electromagnetic forces, the polymer molecules are pulled out creating an orientation in the polymer molecule. The use of a 
rotating drum collector with a higher rotation speed results in a more directed pull of the mechanical force on the polymer molecule. This increases the strength of nanofiber mats.

In summary, the increase in tensile strength and tensile modulus is due to the alignment of nanofibers in the mats, the decrease in fiber diameter, and molecular orientation in the amorphous phase of polymer.

Table 3 shows the mechanical properties of nanofiber mats with perpendicularly oriented nanofibers. Comparing with the properties of nanofibers with a parallel orientation, it is easy to observe that there is not a considerable difference when the rotating speed of the drum is 500 and when using the plate static collector. While using a static collector, the nanofibers are randomly distributed, so there is not a visible effect on the strength of the nanofiber mat. As the rotational speed of the drum increased from 1000 to 2500, it was possible to observe a marked difference in the strength between the parallel and perpendicular orientated nanofibers. This proves that the orientations of the nanofiber has a direct effect on the durability of nanofiber mats; hence, when the orientation of fibers increases, the strength of nanofiber mats increases as well. In addition, it is possible to notice that the elongation at break increased for those samples with perpendicular orientated nanofibers

Table 3. Mechanical properties of PVC nanofiber mats with perpendicular orientation nanofibers.

\begin{tabular}{cccc}
\hline Rotation Speed $(\mathbf{r p m})$ & $\begin{array}{c}\text { Tensile Strength, } \\
\boldsymbol{\sigma}_{\text {at break }}(\mathbf{M P a})\end{array}$ & $\begin{array}{c}\text { Young's Modulus, } \\
\mathbf{E}(\mathbf{M P a})\end{array}$ & $\begin{array}{c}\text { Elongation at Break, } \\
\boldsymbol{\varepsilon}_{\text {at break }}(\mathbf{\%})\end{array}$ \\
\hline 0 & $2.1 \pm 0.1$ & $60 \pm 15$ & $63 \pm 6$ \\
100 & $2.0 \pm 0.6$ & $48 \pm 9$ & $74 \pm 8$ \\
1500 & $0.9 \pm 0.1$ & $20 \pm 6$ & $66 \pm 8$ \\
2000 & $1.0 \pm 0.1$ & $11 \pm 4$ & $80 \pm 16$ \\
2500 & $0.9 \pm 0.3$ & $23 \pm 4$ & $100 \pm 8$ \\
\hline
\end{tabular}

Figure 7 shows the plots of tensile strength and Young's modulus, versus the FFT alignment value. The graphs show that with an increase in the FFT alignment value of the nanofiber in the mat, the mechanical properties of the mats increased for those mats with a parallel oriented nanofiber. This effect can be explained as a result of an increase in the degree of the orientation of nanofibers and PVC molecules inside the fiber. However, for samples with a perpendicular fiber arrangement, tensile strength and Young's modulus did not present a considerable change. Therefore, the change in fiber orientation is the main cause that leads to the change in the tensile strength and Young's modulus of the nanofiber mats.

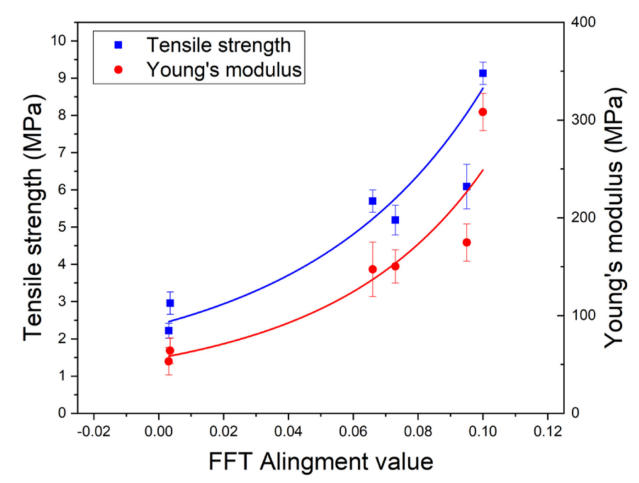

(a)

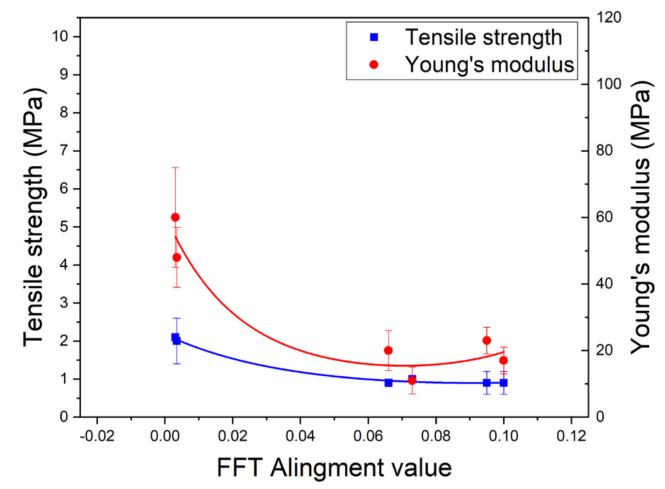

(b)

Figure 7. The dependence of mechanical properties on Fast Fourier Transformation (FFT) alignment value: (a)—nanofibers oriented in a parallel direction; (b) - nanofibers oriented in a perpendicular direction. 
The results of the TGA analysis showed that the TGA curve for the initial PVC granules and the nanofiber mats is the same and has two stages of thermal degradation (Figure 8). The first stage of thermal degradation starts at $233^{\circ} \mathrm{C}$ and the second stage starts at $320^{\circ} \mathrm{C}$. The thermal degradation of PVC nanofibers proceeds in the same way as, for PVC powder. The results showed that PVC powder and PVC nanofiber presented three degradation steps, in which PVC nanofibers lost less volume at each step [39]. The thermal degradation values for PVC nanofiber mats samples obtained from different rotation speeds were the same.

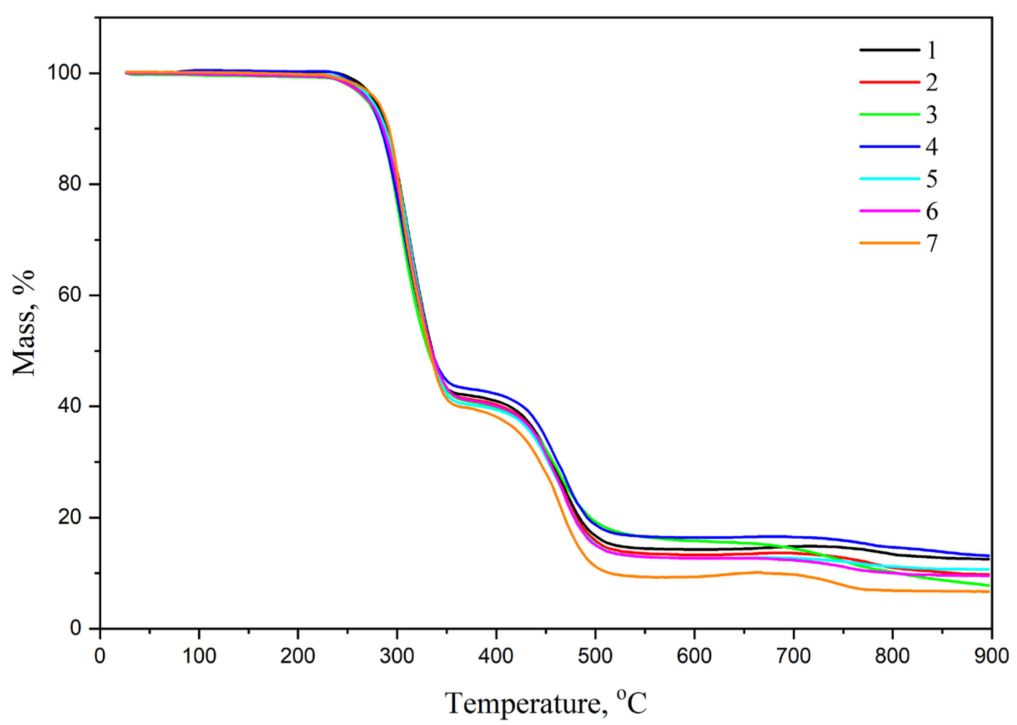

Figure 8. Thermograms for PVC: $1-0 \mathrm{rpm}$; 2-500 rpm; 3-1000 rpm; 4-1500 rpm; 5-2000 rpm; 6-2500 rpm; 7-PVC powder.

Figure 9 shows the result of the DSC analysis. For PVC powder the glass transition temperature $\left(\mathrm{T}_{\mathrm{g}}\right)$ is $83.2^{\circ} \mathrm{C}$, and that for the PVC nanofiber mats is $77.5^{\circ} \mathrm{C}$. PVC nanofiber mats have a lower glass transition temperature than PVC powders. A decrease in the glass transition temperature may be associated with a decrease in the size of the diameter of the fibers with respect to the dimensions of the volumetric PVC [46]. Table 4 shows that the glass transition temperatures of PVC nanofibers obtained by electrospinning at different rotational speeds of the drum collector are the same.

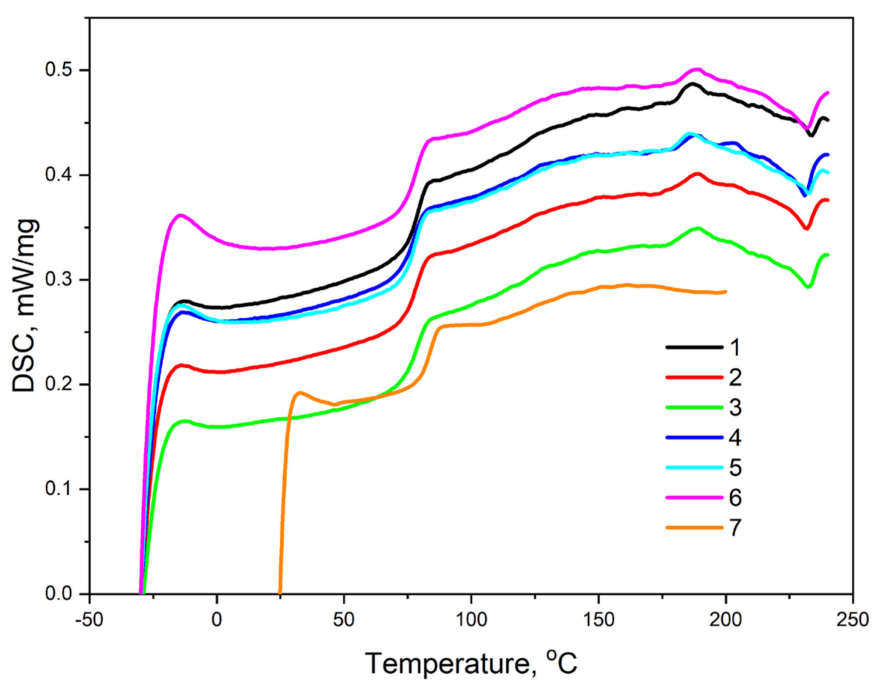

Figure 9. Differential scanning calorimetry (DSC) thermogram of PVC: $1-0 \mathrm{rpm}$; $2-500 \mathrm{rpm}$; 3-1000 rpm; 4-1500 rpm; 5-2000 rpm; 6-2500 rpm; 7-PVC powder. 
Table 4. Glass transition temperature (Tg) of PVC nanofibers and PVC powder.

\begin{tabular}{|c|c|c|c|c|c|c|c|}
\hline \multirow[b]{2}{*}{ Materials } & \multirow[b]{2}{*}{ PVC Powder } & \multicolumn{6}{|c|}{ PVC Nanofiber Mats Obtained By Electrospinning At Different Rotational Speeds } \\
\hline & & 0 (Flat Plate Collector) & 500 & 1000 & 1500 & 2000 & 2500 \\
\hline $\begin{array}{l}\text { The glass transition } \\
\text { temperature }(\mathrm{Tg}),{ }^{\circ} \mathrm{C}\end{array}$ & 83.2 & 77.9 & 77.5 & 77.9 & 76.8 & 77.4 & 77.5 \\
\hline
\end{tabular}

\section{Conclusions}

Fiber morphology, which includes the orientation of the nanofiber mat and individual characteristics of the nanofiber, are the main factors that affect the mechanical properties of the nanofiber mats. Therefore, to improve the mechanical properties of the nanofiber mats, it is necessary to improve the morphology and change the individual characteristics of the nanofiber in the mats. In this study, we were able to change the morphology of the nanofibers, by using a rotating drum collector. Oriented PVC nanofibers were obtained by electrospinning at a rotational speed of the drum collector from 0 to $2500 \mathrm{rpm}$. Based on SEM images, the diameter of the nanofibers varied from $313 \pm 52$ to $229 \pm 47 \mathrm{~nm}$, in relation to the increase in the collector's rotation speed, from 0 to $2500 \mathrm{rpm}$. Additionally, the tensile strength increased from $2.2 \pm 0.2 \mathrm{MPa}$ to $9.1 \pm 0.3 \mathrm{MPa}$, the Young's modulus from $53 \pm 14$ to $308 \pm 19 \mathrm{MPa}$. Moreover, we found that the change in fiber orientation is the main cause that leads to the change in the mechanical properties of the nanofiber mats. Furthermore, it was shown that an increase in the rotation speed of the collector leads to an increase in the degree of orientation of PVC nanofibers and an increase in mechanical properties. DSC measurements showed that the glass transition temperature of nanofibers is lower than that of powders PVC.

Author Contributions: Conceptualization, M.V.U.; formal analysis, Q.P.L., R.O.O.; investigation, Q.P.L., R.O.O., M.A.B.; resources M.V.U.; writing—original draft preparation, writing—review and editing, Q.P.L., R.O.O.; supervision, M.V.U.; funding acquisition, M.V.U. All authors have read and agreed to the published version of the manuscript.

Funding: This work was financially supported by the Government of Russian Federation (Grant 08-08). Institutional Review Board Statement: Not applicable.

Informed Consent Statement: Not applicable.

Data Availability Statement: Data sharing not applicable to this article as no datasets were generated or analysed during the current study.

Conflicts of Interest: The authors declared that they have no conflict of interest in this work.

\section{References}

1. Rahman, M.M. Introductory Chapter: Overview of Nanofibers. Nanofiber Res. Reach. New Heights 2016. [CrossRef]

2. Dastidar, D.G.; Chakrabarti, G. Thermoresponsive Drug Delivery Systems, Characterization and Application. In Applications of Targeted Nano Drugs and Delivery Systems; Elsevier BV: Amsterdam, The Netherlands, 2019; pp. 133-155.

3. Akduman, C.; Kumbasar, E.P.A. Electrospun Polyurethane Nanofibers. Asp. Polyurethanes 2017, 17-52. [CrossRef]

4. Bhardwaj, N.; Kundu, S.C. Electrospinning: A Fascinating Fiber Fabrication Technique. Biotechnol. Adv. 2010, 28, 325-347. [CrossRef] [PubMed]

5. Zhu, M.; Han, J.; Wang, F.; Shao, W.; Xiong, R.; Zhang, Q.; Pan, H.; Yang, Y.; Samal, S.K.; Zhang, F.; et al. Electrospun Nanofibers Membranes for Effective Air Filtration. Macromol. Mater. Eng. 2017, 302, 1600353. [CrossRef]

6. Shabafrooz, V.; Mozafari, M.; Vashaee, D.; Tayebi, L. Electrospun Nanofibers: From Filtration Membranes to Highly Specialized Tissue Engineering Scaffolds. J. Nanosci. Nanotechnol. 2014, 14, 522-534. [CrossRef]

7. Lv, D.; Wang, R.; Tang, G.; Mou, Z.; Lei, J.; Han, J.; De Smedt, S.C.; Xiong, R.; Huang, C. Ecofriendly Electrospun Membranes Loaded with Visible-Light-Responding Nanoparticles for Multifunctional Usages: Highly Efficient Air Filtration, Dye Scavenging, and Bactericidal Activity. ACS Appl. Mater. Interfaces 2019, 11, 12880-12889. [CrossRef]

8. Zhu, M.; Xiong, R.; Huang, C. Bio-Based and Photocrosslinked Electrospun Antibacterial Nanofibrous Membranes for Air Filtration. Carbohydr. Polym. 2019, 205, 55-62. [CrossRef] 
9. Ma, W.; Li, Y.; Zhang, M.; Gao, S.; Cui, J.; Huang, C.; Fu, G. Biomimetic Durable Multifunctional Self-Cleaning Nanofibrous Membrane with Outstanding Oil/Water Separation, Photodegradation of Organic Contaminants, and Antibacterial Performances. ACS Appl. Mater. Interfaces 2020, 12, 34999-35010. [CrossRef]

10. Cui, J.; Li, F.; Wang, Y.; Zhang, Q.; Ma, W.; Huang, C. Electrospun Nanofiber Membranes for Wastewater Treatment Applications. Sep. Purif. Technol. 2020, 250, 117116. [CrossRef]

11. Zhang, M.; Ma, W.; Cui, J.; Wu, S.; Han, J.; Zou, Y.; Huang, C. Hydrothermal synthesized UV- Resistance and Transparent Coating Composited Superoloephilic Electrospun Membrane for High Efficiency Oily Wastewater Treatment. J. Hazard. Mater. 2020, 383, 121152. [CrossRef] [PubMed]

12. Xu, C.; Inai, R.; Kotaki, M.; Ramakrishna, S. Electrospun Nanofiber Fabrication as Synthetic Extracellular Matrix and Its Potential for Vascular Tissue Engineering. Tissue Eng. 2004, 10, 1160-1168. [CrossRef] [PubMed]

13. Nagarajan, S.; Belaid, H.; Pochat-Bohatier, C.; Teyssier, C.; Iatsunskyi, I.; Coy, E.; Balme, S.; Cornu, D.; Miele, P.; Kalkura, N.S.; et al. Design of Boron Nitride/Gelatin Electrospun Nanofibers for Bone Tissue Engineering. ACS Appl. Mater. Interfaces 2017, 9 , 33695-33706. [CrossRef] [PubMed]

14. Wei, Q.; Wei, A. Functional Nanofibers for Drug Delivery Applications. Funct. Nanofibers Appl. 2012, 153-170. [CrossRef]

15. Gao, S.; Tang, G.; Hua, D.; Xiong, R.; Han, J.; Jiang, S.; Zhang, Q.; Huang, C. Stimuli-Responsive Bio-Based Polymeric Systems and Their Applications. J. Mater. Chem. B 2019, 7, 709-729. [CrossRef] [PubMed]

16. Hua, D.; Liu, Z.; Wang, F.; Gao, B.; Chen, F.; Zhang, Q.; Xiong, R.; Han, J.; Samal, S.K.; De Smedt, S.C.; et al. pH Responsive Polyurethane (Core) and Cellulose Acetate Phthalate (Shell) Electrospun Fibers for Intravaginal Drug Delivery. Carbohydr. Polym. 2016, 151, 1240-1244. [CrossRef]

17. Jiang, S.; Chen, Y.; Duan, G.; Mei, C.; Greiner, A.; Agarwal, S. Electrospun Nanofiber Reinforced Composites: A Review. Polym. Chem. 2018, 9, 2685-2720. [CrossRef]

18. Ding, B.; Wang, M.; Wang, X.; Yu, J.; Sun, G. Electrospun Nanomaterials for Ultrasensitive Sensors. Mater. Today 2010, 13, 16-27. [CrossRef]

19. Myndrul, V.; Coy, E.; Bechelany, M.; Iatsunskyi, I. Photoluminescence Label-Free Immunosensor for the Detection of Aflatoxin B1 Using Polyacrylonitrile/Zinc Oxide Nanofibers. Mater. Sci. Eng. C 2021, 118, 111401. [CrossRef]

20. Yao, J.; Bastiaansen, C.W.; Peijs, T. High Strength and High Modulus Electrospun Nanofibers. Fibers 2014, 2, 158-186. [CrossRef]

21. Linh, N.T.B.; Lee, B.-T. Electrospinning of Polyvinyl Alcohol/Gelatin Nanofiber Composites and Cross-Linking for Bone Tissue Engineering Application. J. Biomater. Appl. 2012, 27, 255-266. [CrossRef]

22. El-Messiry, M.; Fadel, N. The Tensile Properties of Electrospun Poly Vinyl Chloride and Cellulose Acetate (PVC/CA) Bi-Component Polymers Nanofibers. Alex. Eng. J. 2019, 58, 885-890. [CrossRef]

23. Huang, L.; Arena, J.T.; Manickam, S.S.; Jiang, X.; Willis, B.G.; McCutcheon, J.R. Improved Mechanical Properties and Hydrophilicity of Electrospun Nanofiber Membranes for Filtration Applications by Dopamine Modification. J. Membr. Sci. 2014, 460, $241-249$. [CrossRef]

24. Huang, L.; Manickam, S.S.; McCutcheon, J.R. Increasing Strength of Electrospun Nanofiber Membranes for Water Filtration Using Solvent Vapor. J. Membr. Sci. 2013, 436, 213-220. [CrossRef]

25. Guibo, Y.; Qing, Z.; Yahong, Z.; Yin, Y.; Yumin, Y. The Electrospun Polyamide 6 Nanofiber Membranes Used as High Efficiency Filter Materials: Filtration Potential, Thermal Treatment, and Their Continuous Production. J. Appl. Polym. Sci. 2013, 128, 1061-1069. [CrossRef]

26. Yu, L.; Shao, Z.; Xu, L.; Wang, M. High Throughput Preparation of Aligned Nanofibers Using an Improved Bubble-Electrospinning. Polym. 2017, 9, 658. [CrossRef] [PubMed]

27. Bazrafshan, Z.; Stylios, G.K. Custom-Built Electrostatics and Supplementary Bonding in the Design of Reinforced Collagen-gP(methyl methacrylate-co-ethyl acrylate)/Nylon 66 Core-Shell Fibers. J. Mech. Behav. Biomed. Mater. 2018, 87, 19-29. [CrossRef] [PubMed]

28. Arras, M.M.L.; Grasl, C.; Bergmeister, H.; Schima, H. Electrospinning of Aligned Fibers with Adjustable Orientation Using Auxiliary Electrodes. Sci. Technol. Adv. Mater. 2012, 13, 35008. [CrossRef] [PubMed]

29. Xu, C.; Inai, R.; Kotaki, M.; Ramakrishna, S. Aligned Biodegradable Nanofibrous Structure: A Potential Scaffold for Blood Vessel Engineering. Biomaterials 2004, 25, 877-886. [CrossRef]

30. Baji, A.; Mai, Y.-W.; Wong, S.-C.; Abtahi, M.; Chen, P. Electrospinning of Polymer Nanofibers: Effects on Oriented Morphology, Structures and Tensile Properties. Compos. Sci. Technol. 2010, 70, 703-718. [CrossRef]

31. Zhu, H.; Qiu, S.; Jiang, W.; Wu, D.; Zhang, C. Evaluation of Electrospun Polyvinyl Chloride/Polystyrene Fibers As Sorbent Materials for Oil Spill Cleanup. Environ. Sci. Technol. 2011, 45, 4527-4531. [CrossRef]

32. Alarifi, I.M.; Alharbi, A.R.; Khan, M.; Khan, W.S.; Usta, A.; Asmatulu, R. Water Treatment using Electrospun PVC/PVP Nanofibers as Filter Medium. Int. J. Mater. Sci. Res. 2018, 2, 43-49. [CrossRef]

33. Es-saheb, M.; Elzatahry, A.A.; Sherif, E.S.M.; Alkaraki, A.S.; Kenawy, E.R. A Novel Electrospinning Application for Polyvinyl Chloride Nanofiber Coating Deposition as a Corrosion Inhibitor for Aluminum, Steel, and Brass in Chloride Solutions. Int. J. Electrochem. Sci. 2012, 7, 5962-5976.

34. Nitti, P.; Gallo, N.; Natta, L.; Scalera, F.; Palazzo, B.; Sannino, A.; Gervaso, F. Influence of Nanofiber Orientation on Morphological and Mechanical Properties of Electrospun Chitosan Mats. J. Healthc. Eng. 2018, 2018, 1-12. [CrossRef] 
35. Engel, A.B.; Cherifi, A.; Bechelany, M.; Tingry, S.; Cornu, D. Control of Spatial Organization of Electrospun Fibers in a Carbon Felt for Enhanced Bioelectrode Performance. Chem. Plus Chem. 2015, 80, 440. [CrossRef]

36. Taylor, S.E.; Cao, T.; Talauliker, P.M.; Lifshitz, J. Objective Morphological Quantification of Microscopic Images Using a Fast Fourier Transform (FFT) Analysis. Curr. Protoc. Essent. Lab. Tech. 2013, 7, 1-9. [CrossRef] [PubMed]

37. International Organization for Standardization. Plastics_Determination of Tensile Properties_Part. 3: Test. Conditions for Films and Sheets; British Standard: London, UK, 1995; Volume 3.

38. Ayres, C.E.; Jha, B.S.; Meredith, H.; Bowman, J.R.; Bowlin, G.L.; Henderson, S.; Simpson, D.G. Measuring Fiber Alignment in Electrospun Scaffolds: A User's Guide to the 2d Fast Fourier Transform Approach. J. Biomater. Sci. Polym. Ed. 2008, $19,603-621$. [CrossRef]

39. Carrizales, C.; Pelfrey, S.; Rincon, R.; Eubanks, T.M.; Kuang, A.; McClure, M.J.; Bowlin, G.L.; Macossay, J. Thermal and Mechanical Properties of Electrospun PMMA, PVC, Nylon 6, and Nylon 6,6. Polym. Adv. Technol. 2008, 19, 124-130. [CrossRef]

40. Li, W.-J.; Mauck, R.L.; Cooper, J.A.; Yuan, X.; Tuan, R.S. Engineering Controllable Anisotropy in Electrospun Biodegradable Nanofibrous Scaffolds for Musculoskeletal Tissue Engineering. J. Biomech. 2007, 40, 1686-1693. [CrossRef]

41. Kim, G.H. Electrospun PCL Nanofibers with Anisotropic Mechanical Properties as a Biomedical Scaffold. Biomed. Mater. 2008, 3 , 025010. [CrossRef]

42. Wong, S.-C.; Baji, A.; Leng, S. Effect of Fiber Diameter on Tensile Properties of Electrospun Poly ( $\varepsilon$-caprolactone). Polymers 2008, 49, 4713-4722. [CrossRef]

43. Arinstein, A.; Burman, M.; Gendelman, O.; Zussman, E. Effect of Supramolecular Structure on Polymer Nanofibre Elasticity. Nat. Nanotechnol. 2007, 2, 59-62. [CrossRef] [PubMed]

44. Chew, S.Y.; Hufnagel, T.C.; Lim, C.T.; Leong, K.W. Mechanical Properties of Single Electrospun Drug-Encapsulated Nanofibres. Nanotechnology 2006, 17, 3880-3891. [CrossRef] [PubMed]

45. Gu, S.-Y.; Wu, Q.-L.; Ren, J.; Vancso, G. Mechanical Properties of a Single Electrospun Fiber and Its Structures. Macromol. Rapid Commun. 2005, 26, 716-720. [CrossRef]

46. Wang, H.; Chang, T.; Li, X.; Zhang, W.; Hu, Z.; Jonas, A.M. Scaled Down Glass Transition Temperature in Confined Polymer Nanofibers. Nanoscale 2016, 8, 14950-14955. [CrossRef] [PubMed] 